\title{
The Experience of Using Autonomous Drifters for Studying the Ice Fields and the Ocean Upper Layer in the Arctic
}

\author{
S.V. Motyzhev ${ }^{*}$, E.G. Lunev, A.P. Tolstosheev \\ Marine Hydrophysical Institute, Russian Academy of Sciences, Sevastopol, Russian Federation \\ *e-mail: smotyzhev@mail.ru
}

\begin{abstract}
The constructional and operational features of the BTC60/GPS/ice temperature-profiling drifters, developed in Marine Hydrophysical institute RAS for investigation of polar areas, are considered in this article. The drifters operated in completely automatic mode measuring air pressure, water temperatures at 17 depths down to $60 \mathrm{~m}$, ocean pressures at 20, 40 and $60 \mathrm{~m}$ nominal depths and current locations. Accuracies of measurements were: $+/-2 \mathrm{hPa}$ for air pressure, $+/-0.1^{\circ} \mathrm{C}$ for temperatures, $+/-30 \mathrm{hPa}$ for ocean pressure, $60 \mathrm{~m}$ for locations. Iridium satellite communication system was used for data transfer. Time delay between sample and delivery to a user did not exceed 10 minutes. More than 30 thermodrifters were developed in the Beaufort Sea - Canada Basin and central Arctic for the period from September 2012 to September 2014. Total duration of drifting buoys in operation was more of 4800 days. It was accepted the data of hourly samples about variability of ice-flows and ice field as a whole movements, thermo processes within upper water layer below ice, air pressure in near surface atmosphere of the Arctic region. The article includes some results of statistical analysis of data from drifter ID247950, the 3-year trajectory of which depended on the processes of transfer and evolution of ice fields in the Beaufort Sea - Canada Basin. Over a long period of time the Arctic buoy in-situ experiments allowed resulting about capability and reasonability to create reliable, technological and low-cost buoy network on basis of BTC60/GPS/ice drifters to monitor Arctic area of the World Ocean.
\end{abstract}

Keywords: temperature-profiling drifter, ice field, temperature profile, upper ocean, Arctic observation.

DOI: 10.22449/1573-160X-2017-2-51-64

(C) 2017, S.V. Motyzhev, E.G. Lunev, A.P. Tolstosheev

(C) 2017, Physical Oceanography

Introduction. Special attention to the processes and phenomena occurring in the Arctic Ocean and the circumpolar seas on the one hand and the lack of oceanographic and meteorological information due to the region features on the other are characteristic of the current stage of the development of the Arctic region. A great number of publications are devoted to the analysis of the problem of the ice cover upper layer state operational monitoring, including the subglacial ocean layer and the near-surface atmosphere in the Arctic region with the required spatial-temporal resolution. The essence of these publications in terms of the assessment of the observational network current state is briefly described in [1]. Systematizing the available data on the tools of the Arctic observation, the author concludes that, although polar studies with various purposes are extremely relevant, their practical implementation remains technically and organizationally difficult and expensive. It should be noted with regret that the instrumentation stock considered in [1] is represented exclusively by foreign measuring tools, and the Arctic zone of the Russian Federation is the least provided with observations. According to the data given on the website [2], due to the massive decline in polar observations in the 1990s even the level of the minimum sufficient density of observations on the criteria of climate monitoring and long-term weather forecasting is not reached at the present time. The lack of primary data has a negative effect on the quality of hydrometeorological forecasts, thus the prognostic activity is often ineffective. 
For all these reasons, the urgency of the goal of the operative complex monitoring of the atmosphere - ice - ocean Arctic system setting becomes apparent. To a certain extent, the solution of this problem is related to the works of Marine Hydrophysical Institute (MHI) of the Russian Academy of Sciences on the development of drifter observation technology methods and tools and their reduction to the practice of research in the Arctic region of the World Ocean. In the present paper the specialized MHI drifters intended for use in the polar conditions are considered and certain results of long-term in situ drifter experiments carried out in the Arctic Ocean and the circumpolar seas are given. The materials are aimed at substantiating the possibility and feasibility of constructing a reliable, technological and costeffective drifter observational network as an integral part of a stable system of the Arctic region operational observations.

Features of drifter technology of the Arctic region observations. In the past two decades the autonomous drifting data collection platforms (surface drifters) have become the main source of systematic operative contact information on the ocean upper layer state and the near-water atmosphere. The data is transmitted to the users through the channels of Argos or Iridium satellite communication systems. Since 2008 a permanent observational network consisting of 1.250 drifters of various modifications (this provides an average spatial resolution of $500 \times 500 \mathrm{~km}$ ) is maintained in the World Ocean. Drifting buoy of SVP type developed in early 1990s within the framework of the World Climate Research Programme (WCRP) is a basic component of drifter observational network.

During the last 15 years MHI made a significant contribution to the drifter technology development. The research carried out at the Institute is aimed at maintaining a standard observational network and, mainly, at creating new drifter environment monitoring tools and introducing them into the practice of the World Ocean observations.

A direction oriented towards the creation of methods and tools for Polar Regions observation is developed within the framework of drifter technology in MHI since 2008. Technical and methodological solutions implemented in the first polar drifter experiments and having passed long-term tests in the Arctic conditions were the basis for the development of specialized autonomous tools for the research of water column and the ice cover of the Arctic and methods of their application. Wide range of developments performed to date is represented by two main modifications: satellite radiobeacons and temperature-profiling drifters. Satellite radiobeacons are intended for operational monitoring of ice feature (icebergs, glaciers) trajectories, temperature-profiling drifters - for operational monitoring of thermal processes in the upper (including the subglacial) ocean layer and long-term observations over ice fields in the Arctic Ocean and the polar seas. Both modifications suggest the possibility of air pressure measurements.

Regardless of the types of devices, all the stages of their development, production and testing were subject to the following general principles: simplicity of delivery and no special preparation technology for the deployment; long-term reliability of metrological and operational characteristics for the autonomous operation under the conditions of the Arctic region factors effect; relatively low cost. It was this approach that provided a development of a globally competitive stock of polar 
research tools. Further, the structural and operational features of thermoprofiling drifters and some results of their application are considered in more detail.

Temperature-profiling drifters for the research of Arctic region of the World Ocean ("ice" thermodrifters) are the modification of temperature-profiling quasi-Langrangian drifter SVP-BTC80/GPS [4] developed in MHI in 2004. To date, the technology of research using the thermodrifters has become a permanent component of modern system of the ocean operational observations.

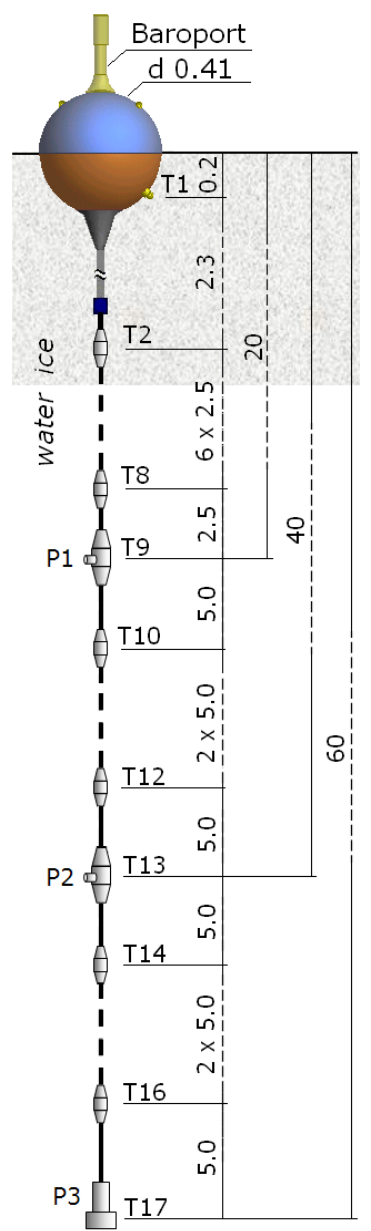

Fig. 1. The design of BTC60/GPS/ice "ice" thermosdrifter (the distance between the sensors is in meters)

the coordinates $-50 \mathrm{~m}$

The design of "ice" thermodrifter of BTC60/GPS/ice type is represented in Fig. 1. A spherical body (of $41 \mathrm{~cm}$ diameter) contains a secondary converter with an air pressure measurement module, a GPS global positioning receiver, Iridium satellite communication system modem, barometric port and the batteries. A thermo-line (into which temperature and hydrostatic pressure sensors are integrated) of $60 \mathrm{~m}$ length is connected to the bottom of the body.

Thermal line informational-measuring system is implemented on the basis of MicroLAN network standard [5]. Integral digital thermometers of DS18B20 (Dallas Semiconductor) type are used as temperature converters in it. MicroLAN network standard supports the exchange protocol and provides power to all thermal line sensors on a single "twisted pair" bus line which minimizes the transverse size of the thermal line and thereby reduces its hydrodynamic resistance. The diameter of the thermal line does not exceed $13 \mathrm{~mm}$, the diameters of the bodies of temperature and hydrostatic pressure sensors are 20 and $40 \mathrm{~mm}$, respectively. Such dimensions of the thermal line (while the drifter total mass is under $30 \mathrm{~kg}$ ) significantly simplify drifter delivery and deployment. This is of a great importance for the studies in the polar conditions. Drifter design provides the possibility of its setting both on the ice and on the open water surface with a subsequent freezing of the drifter body and the upper part of the thermal line into the ice.

In BTC60/GPS/ice thermodrifter modification air pressure, water temperature at the horizons given in Fig. 1 , hydrostatic pressure at 20, 40 and $60 \mathrm{~m}$ horizons and coordinates are measured. Air pressure measurement errors are less than $2 \mathrm{hPa}$, the ones of the temperature $0.1^{\circ} \mathrm{C}$, hydrostatic pressure errors $-30 \mathrm{hPa}$, the ones of the coordinates $-50 \mathrm{~m}$. The measurements of all the parameters are carried out at the beginning of each hour. The measurement results are transmitted in the messages via the Iridium satellite communication system. Message delivery delay does not exceed $10 \mathrm{~min}$. 
Note that the mentioned measurement horizons should be considered as nominal ones. Real values of the horizons may differ from the nominal ones due to thermal line vertical deviations which are caused by the differences between the velocity of the body drift (the velocity of ice field drift) and the velocities of currents at the profiling depths. The data of hydrostatic pressure sensors allow us to assess the real geometry of thermal line and, consequently, vertical displacement of horizons of temperature sensors position. BTC60/GPS/ice/1ps modification is different in that hydrostatic pressure is measured only at the end of the thermal line (60 m nominal horizon). In this case the real positions of the temperature measurement horizons are assessed by solving the problem of the cable equilibrium in a steady flow [6].

From September 2012 to September 2014 more than 30 thermodrifters developed in MHI were deployed in the Arctic. Thermodrifters were mainly applied within the framework of UpTempO project (University of Washington, USA) [7] of International Arctic Buoy Program (IABP). The operational systematic contact observations of the thermal variability of the upper (including the subglacial) ocean layer and the near-water atmosphere in the polar region are the aim of the project. The tasks of $U p T e m p O$ project were determined by two regions of the drift-monitoring greatest intensity: the Beaufort Sea - the Canadian Basin and the Central Arctic. The trajectories of thermodrifters and detailed statistical information on the results of their application in the project are given in [8].

Further, some of the most interesting results, in our opinion, of thermodrifter monitoring of ice field motion characteristics and thermal variability of the upper subglacial ocean layer are considered. The results of long-term monitoring of near-surface atmosphere layer pressure field over the Arctic region are considered in detail in [9].

Visual analysis of drift trajectories. In the experiments on UpTempO project almost all the drifters were deployed in August - September 2012 and 2013, i.e. in periods when the Arctic ice cover usually reaches the annual minimum. 15 ther-modrifters (total duration of drifts is more than 3000 days) were deployed in the Beaufort Sea - the Canadian Basin, 5 - in the Central Arctic (more than 1800 days of drifts).

The trajectories of thermodrifters (their drift was completely or mostly determined by the ice field drift) are given in Fig. 2. Ice conditions as at time of deployment (September 2013 and September 2014) are marked in white color in the same figure.

In the Beaufort Sea - the Canadian Basin the trajectories of drifters (Fig. 2, $a, b$ ) were determined by the processes of ice formation transport in the Beaufort Gyre. The trajectories of ID242970, ID244950, ID245950 (2013) and ID236150 (2014) drifters reproduced the anticyclonic ice motion around the periphery, the ones of ID238150 and ID239180 drifters (2014) - in the central part of the gyre. Here and further, after the drifter number the year of its deployment is given in the brackets. ID245960 drifter (2013) moved in the ice field from the West to the East through the central part of the gyre, and ID242840 drifter (2013) trajectory was determined by the movement of ice from the central part of the gyre to its eastern tip. The similarity of ID242970 (2013) and ID236150 (2014) drifter trajectories demonstrates the inter-annual repeatability of the ice fields motion characteristics in the region of drifts. 
The trajectories of ID242970 and ID244950 (2013) drifters reproduced the processes of the ice field convergence. At the initial sites drifters moved along different trajectories in the second half of August. Their trajectories almost coincided on August 31. Until the end of February 2014 when ID244950 drifter stopped the data transfer, the drift of both drifters was determined by the movement of consolidated ice field.
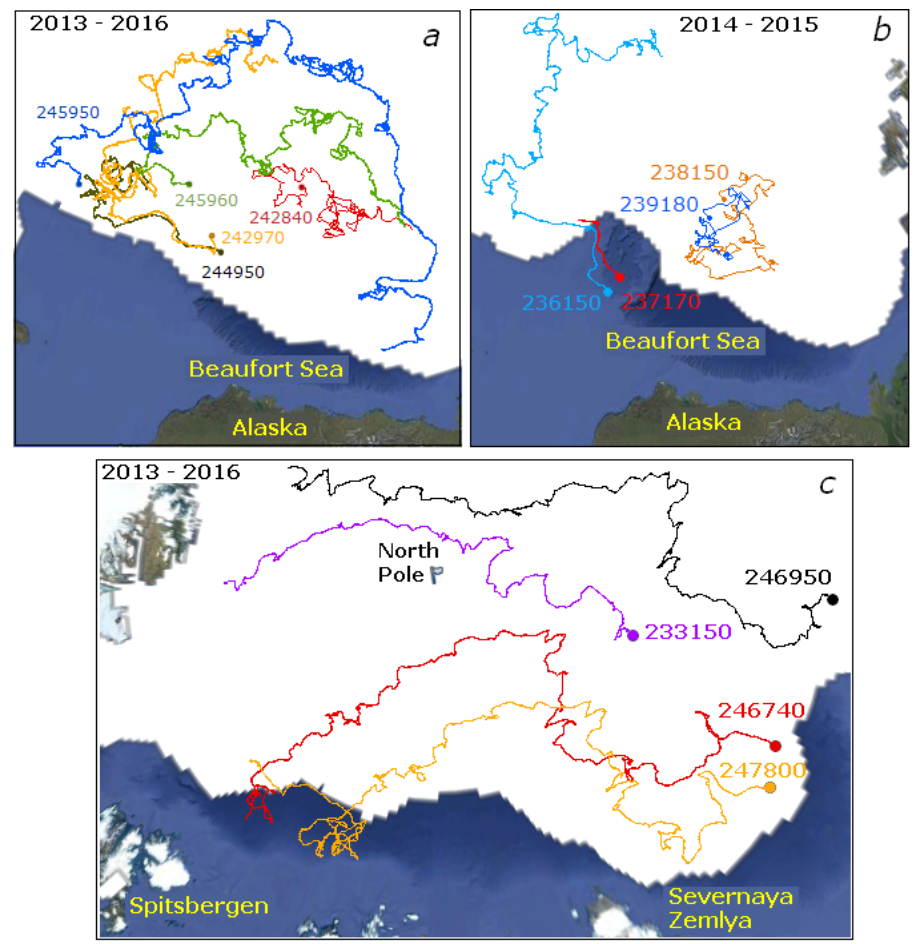

Fig. 2. Drift trajectories of MHI temperature-profiling drifters in the Beaufort Sea - the Canadian Basin. The beginning of the drift: $a$ - in August - September 2013; $b$ - in August - September 2014. The same is for the Central Arctic: the beginning of drift took place in August - September 2013 (c). ID233150 drifter was deployed in September 2014

The initial sections of the trajectories of ID236150 and ID237170 drifters (2014) illustrate the method of their placement on the open water surface with the subsequent freezing of the drifter body and the thermal line upper part into the ice. The drifters were deployed on September 6 and 14 on the ice-free surface of the sea and drifted to the North until mid-October. Approximately on October 15th both drifters froze into the ice and then they moved in the ice fields.

The trajectory of ID245950 drifter (2013), which had been fully operable for almost three years, turned out to be the longest. The drift results are considered in more detail below.

In the Central Arctic (Fig. 2, c) the trajectories of ID246740, ID246950, ID247800 (2013) and ID233150 (2014) drifters were determined by the processes of ice field transarctic transport. At a significant spatial separation of the first three drifters, one can trace the similarity of their trajectories. This indicates the impact of common factors on the drift characteristics. 
Statistical analysis of trajectories. Before turning to the consideration of methodology and the results of the analysis it is necessary to make explanations related to the features of drifter operation under polar conditions. As it was mentioned before, the measurements of all parameters and data transfer are performed at the beginning of each hour. However, in some cases not all data is delivered to the user. The omissions are mainly due to the shielding of the drifter body by the snow or (and) its too large inclination. The latter is possible when setting the drifter on the open water with the subsequent uncontrolled freezing into the ice (ID236150 and ID237170 drifters). Therefore, to obtain statistically significant estimations only the data of those drifters whose time series of coordinated contained no more than 15 $\%$ of omissions and the greatest durability of the missed data did not exceed $4 \mathrm{~h}$ were considered. Statistical characteristics of the ice field motion were assessed by the trajectories obtained by linear interpolation of such series for $1 \mathrm{~h}$ interval.

Statistical characteristics of drifts were calculated by the coordinates of drifters measured by built-in GPS receivers with $\Delta_{S} \leq 50 \mathrm{~m}$ error. With $\tau=1 \mathrm{~h}$ time interval between the measurements the error of drift velocity assessment is $\Delta V=\frac{\sqrt{2} \Delta_{S}}{\tau} \leq 2 \mathrm{~cm} / \mathrm{s}$.

The trajectory of ID245950 drifter which was installed on the water surface on August 30, 2013 and frozen into the ice by October 11 is given in Fig. 3, a. Over the next almost three years the drifter was fully operable and this allowed us to obtain unique data series on the processes of transport and evolution of ice formations, the variability of atmospheric pressure and the thermal structure of the upper layer (including the subglacial one) of the sea. The power supply life ended on August 16, 2016 and the drifter stopped the data transmission.

In 1082 days the drifter passed $8926 \mathrm{~km}$. Average drift velocity made up $0.1 \mathrm{~m} / \mathrm{s}$, the maximum one $-0.8 \mathrm{~m} / \mathrm{s}(16.07 .2016,5: 00)$.

Time series of data obtained for the entire duration of the drifter operation were divided into seasonal blocks "winter" and "summer" for the further analysis. "Winter" blocks contain the data obtained while drifting in the ice field with a high ice concentration (compact ice), "summer" blocks - on a freely floating ice floe or in the open water. The belonging of data to one or another season was determined by the drifter body temperature and $D_{v}(t)$ sliding dispersion of high-frequency drift velocity component. The sliding dispersion was assessed in the following way. From the time series of the velocity, calculated from the coordinates of the drifter, relatively high-frequency mesoscale fluctuations were distinguished. From the velocity time series calculated by the drifter coordinates relatively high-frequency mesoscale fluctuations were singled out. Butterworth filter of higher frequencies with $0.85 f_{i}$ cut-off frequency where $f_{i}$ is a frequency of inertial oscillations, nominal value of which made up $\sim 1 / 12.2$ cycle/h at the considered drift section, was applied. The filtering was carried out using the filtfilt function implemented in the Matlab environment, which allows one to compensate the phase shift (introducing during the normal filtration) by bi-directional signal processing, i.e. without adding a time delay to the filtration result. $D_{V}(t)$ sliding dispersion of drift velocity was estimated according to the time series thus obtained for the "window" of 5 days width with $1 \mathrm{~h}$ shift. The assessment results are represented in Fig. 3, b. The graph of time series of SST drifter body temperature is also given there. 

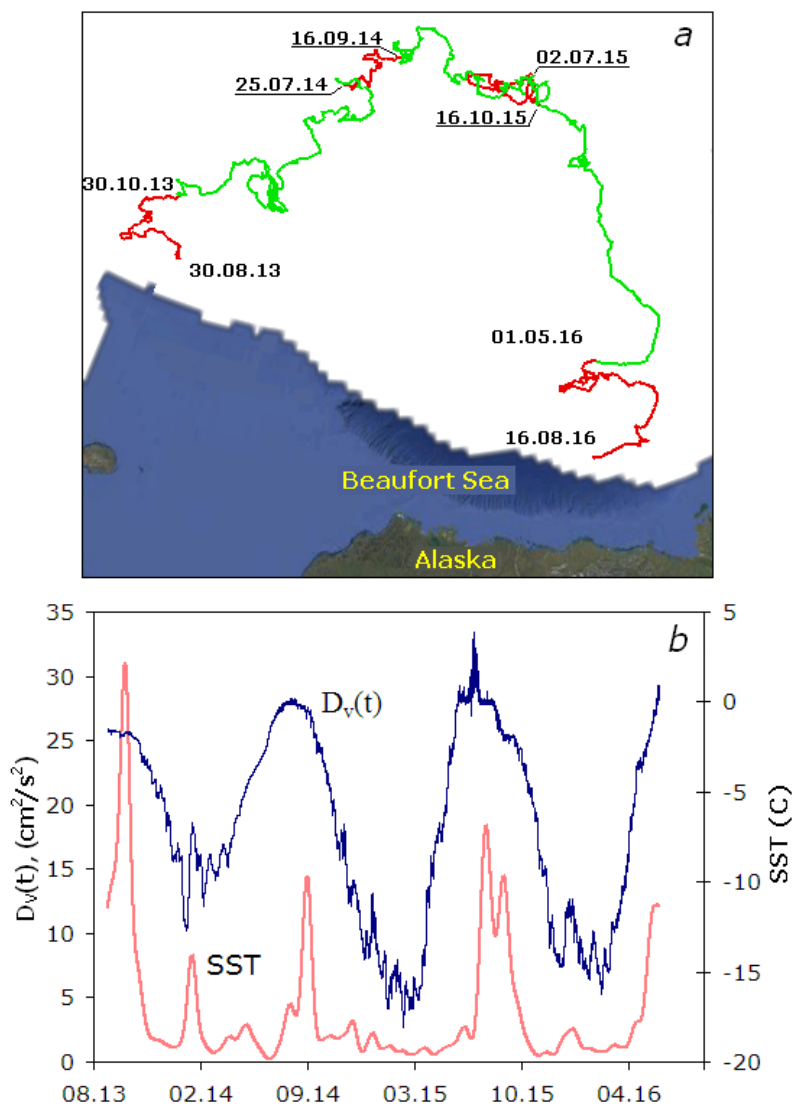

Fig. 3. Trajectory $(a)$, sliding dispersion $D_{V}(t)$ of drift velocity and SST body temperature $(b)$ according to data of ID245950 drifter. The trajectory sections related to "winter" seasons are denoted in green, the ones for the "summer" seasons - in red. The white color on the map (a) indicates the ice situation for the deployment time (September 2013)

It was assumed that small values of the sliding velocity dispersion at a drifter body temperature below $-1.8^{\circ} \mathrm{C}$ (the freezing point of the Arctic waters) correspond to the sections of the drifter movement in an ice field with a high ice concentration, higher dispersion values at a drifter body temperature above $-1.8^{\circ} \mathrm{C}-$ to the sections of a drifter movement on a free floating ice floe or in the open waters. In Fig. 3, $a$ trajectory fragments relating to the "summer" season are represented in red, the ones relating to "winter" season - in green.

The duration of data series in all the sections under consideration provide statistically significant estimation of drift characteristics in the mesoscale and synoptic ranges.

Frequency structure of velocity component fluctuations was estimated according to power spectral densities (PSD) which were calculated using the method of averaging the modified periodograms or the Welch method. Initial time series of data was divided into overlapping segments, and the data of each obtained segment was multiplied by the Parzen window function. The modified periodograms were calculated for the segments weighed in this way. The obtained PSD estimation is a result of averaging of periodograms of all segments. Such method provides smooth PHYSICAL OCEANOGRAPHY NO. 2 (2017) 
and statistically stable estimates for a finite data series. PSD assessment of was carried out according to the program implemented in Matlab environment using pwelch function.

When assessing PSD in the mesoscale range of variability, it is necessary to take into account the fact that the frequencies of inertial oscillations at the drift latitudes are comparable with $f_{s}$ frequency of semidiurnal tidal oscillations and it is problematic to solve them even at the small values of the degree of freedom. The difference between these two types of oscillations can be found using the method of rotational components. The method allows us to divide the velocity vector into the components of clockwise and counterclockwise rotation directions. The first ones correspond to negative, the second - to positive frequencies. Power spectral densities of these components were calculated using the Fourier transform by the following formula:

$$
P(f)=\frac{1}{N}\left\{\sum_{t=t_{0}}^{t_{1}-\Delta t} \mathrm{e}^{-i 2 \pi f t}[\mathrm{u}(t)+i v(t)]\right\}^{2},
$$

where $N$ is a number coordinate measurements at $t_{0}-t_{1}$ time interval; $\Delta t$ is a discreteness of measurements; $f$ is a frequency; $u(t), v(t)$ are the velocity components according to the drift data at the same time interval.

PSD $P_{c w}(-f)$ and $P_{c c w}(f)$ components of velocity vector (calculated by this formula for the section of ID245950 drifter trajectory over 16.09.2014 - 02.07.2015 period (Fig. 3, a)) corresponding to the clockwise and counterclockwise rotation directions are represented in Fig. 4.

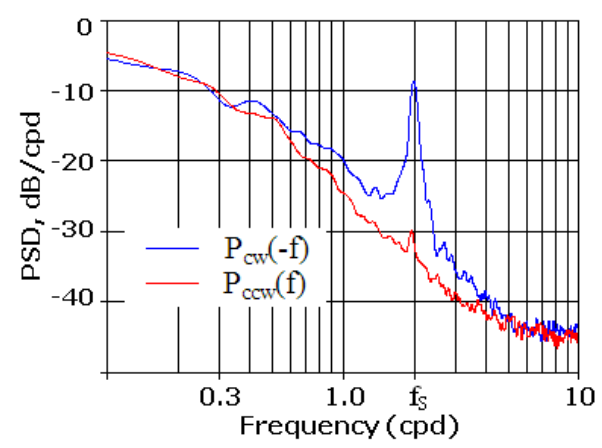

Fig. 4. The graphs of PSD $P_{c w}(-f)$ and $P_{c c w}(f)$ components of velocity vector according to the data of ID245950 drifter at the trajectory section given in Fig. 3, $a(16.09 .2014-02.07 .2015), f_{S}=$ $=2$ cycle/day

PSD graphs are plotted with regard to $f$ frequency modulus and contain two statistically significant local maxima. The maximum on the 2 cycle/day negative frequency is due to both inertial oscillations (their frequency at the middle latitude of the drift section under consideration makes up 1.98 cycle/day) and semidiurnal tidal oscillations. The maximum on the 2 cycle/day positive frequency (its power is $20 \mathrm{~dB}$ less than the one of the maximum on the negative frequency) is only due to tidal oscillations. Assuming tidal oscillation power maxima independence from the frequency sign, one may suppose that the maximum on the negative 
frequency is mainly due to the energy of inertial oscillations. The estimates of PSD components of drift velocity given below were obtained under this assumption.

Long-term series of drifter coordinate measurements provide a statistically significant estimation of inter-seasonal and interannual variability of drift energy characteristics. To assess the synoptic variability of high-frequency velocity oscillations, the entire drift trajectory was divided into monthly fragments according to which monthly estimates of PSD components of drift velocity were calculated. When calculating the spectral characteristics time series were divided into 6 overlapping segments. Overlapping coefficient of the segments made up $50 \%$. As a result, statistically significant estimations of PSD were obtained for each month, the confidence intervals of which at 20 degree of freedom with a probability of 0.95 fall within $(0.36-0.84) \cdot$ PSD limits.

Monthly energy characteristics of drift in the mesoscale variability range were compared by the parameter $\eta=S\left(f_{i}\right) / S\left(f_{L}\right)$ - the relation of PSD local maximum amplitude in the proximity of $f_{i}$ inertial frequency to the PSD value on $f_{L}=0.8 f_{i}$ frequency. The results of calculations performed according to ID245950 drifter data are shown in Fig. 5.

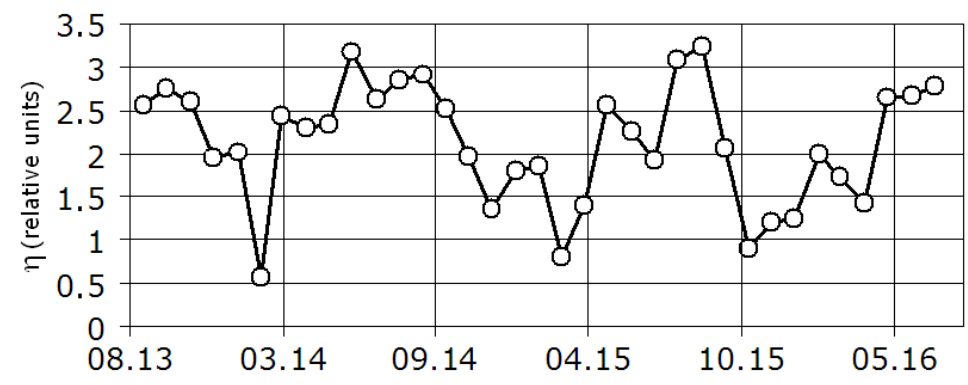

Fig. 5. Time series of $\eta$ parameter according to ID245950 drifter data (explanations are given in the text)

It is obvious from the graph that mesoscale variability of drifter motion energy characteristics has a pronounced seasonal dependence and $\eta$ parameter may be considered as a quantitative measure that characterizes the degree of ice formations concentration.

For singling out the synoptic components, time series of the coordinates were filtered using a low-frequency Butterworth filter with 0.2 cycle/day cutoff frequency. The filtering was carried out in the same way as described above. The distances monthly covered by the drifter (with no regard to high-frequency circulations) were calculated according to "synoptic" drifter trajectory (Fig. 6, $a$ ) obtained as a result of filtering. Temporal variability of such distances is shown in Fig. 6, $b$.

As is obvious from the graph, minimum monthly distances in the synoptic range were recorded in March 2014 (29 km/month), October 2014 (20 km/month), March 2015 (15 km/month) and in June 2016 (26 km/month). The minimums that took place in March are due to drift conditions in the consolidated ice field and the ones that took place in October and June are due significant contribution of mesoscale range circulations to the drift trajectory, which is confirmed by high values of $\eta$ parameter for these months (Fig. 5). 


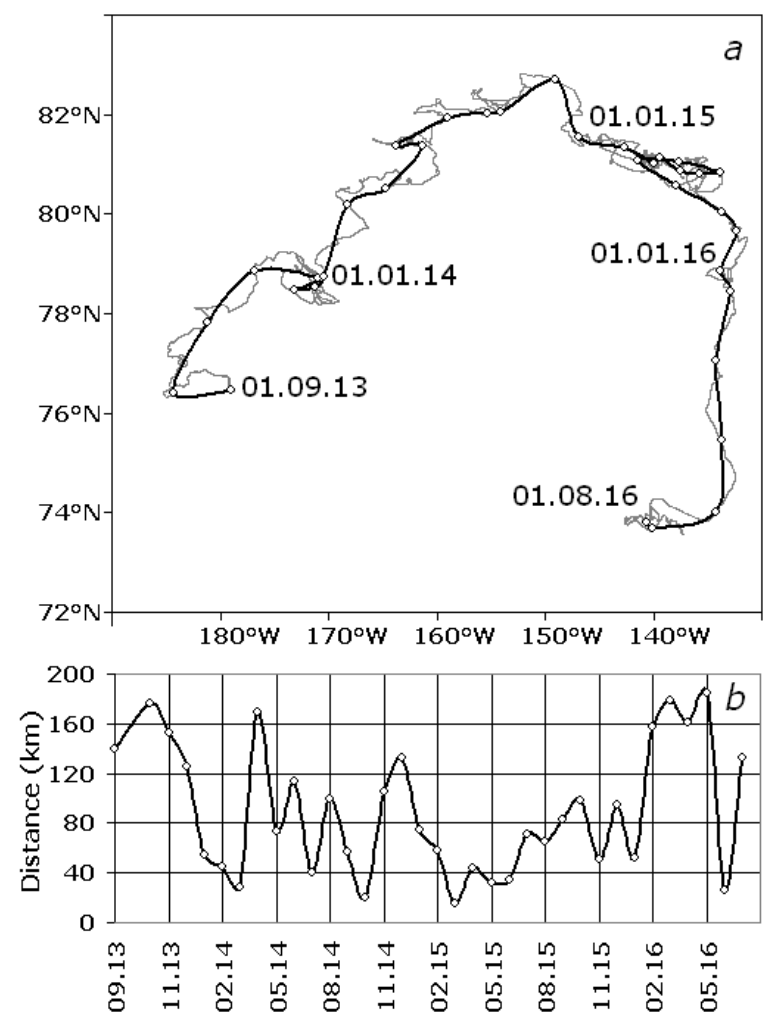

Fig. 6. Trajectories of ID245950 drifter before (thin line) and after (thick line with markers) lowfrequency filtering $(a)$ and time series of monthly distances by the trajectory after low-frequency filtering $(b)$. Temporal interval between the markers makes up 1 month

As is obvious from the graph, minimum monthly distances in the synoptic range were recorded in March 2014 (29 km/month), October 2014 (20 km/month), March 2015 (15 km/month) and in June 2016 (26 km/month). The minimums that took place in March are due to drift conditions in the consolidated ice field and the ones that took place in October and June are due significant contribution of mesoscale range circulations to the drift trajectory, which is confirmed by high values of $\eta$ parameter for these months (Fig. 5).

Statistical information on the experiment carried out in 2013 - 2015 in the Central Arctic (drifter trajectories are represented in Fig. 2, c) is given in the table. In terms of providing the observation effectiveness, an attention should be paid to "duration/distance" column. Comparative analysis reveals the fact that according to representativeness of time series of systematic operative monitoring data the effectiveness of BTC60/GPS/ice "ice" drifter application is significantly higher than the one of any modern contact tool for studying the Polar Regions. Data transmission channels reliability assessments are also given in the table: the users received at least $98 \%$ of the results of measurements carried out with $1 \mathrm{~h}$ interval. This also applies to the results of drifter coordinates measurements according to data of builtin GPS receivers. This provided statistically significant assessments of Langrangian characteristics of ice field drifts. 
Information on drifter experiment carried out in 2013 - 2015 in the Central Arctic

\begin{tabular}{c|c|c|c|c|c|c}
\hline \multirow{2}{*}{$\begin{array}{c}\text { Drifter } \\
\text { number }\end{array}$} & \multicolumn{4}{|c|}{ Drift } & Relative amount & \multicolumn{2}{|c}{ Velocity, m/s } \\
\cline { 2 - 3 } & start & finish & $\begin{array}{c}\text { duration/ } \\
\text { distance, } \\
\text { day/km }\end{array}$ & $\begin{array}{c}\text { ofeceived } \\
\text { messages, } \\
\%\end{array}$ & mean & $\begin{array}{c}\text { Root-mean- } \\
\text { square devi- } \\
\text { ation }\end{array}$ \\
\hline ID246740 & 30.08 .13 & 14.10 .14 & $410 / 4234$ & 99.4 & 0.12 & 0.08 \\
ID246950 & 03.09 .13 & 15.12 .14 & $468 / 3237$ & 98.3 & 0.08 & 0.06 \\
ID247800 & 07.09 .13 & 23.01 .15 & $503 / 5643$ & 99.4 & 0.13 & 0.09 \\
ID233150 & 02.09 .14 & 29.07 .15 & $331 / 2316$ & 98.5 & 0.08 & 0.07 \\
\hline
\end{tabular}

Observations of upper subglacial ocean layer thermal structure. A decrease of sea ice area and thickness which, in its turn, leads to higher atmosphere warming and transport of warmer sub-arctic waters to the circumpolar regions [10 - 12] is an obvious consequence of abnormal (according to observation data obtained in recent years) warming of the Arctic Ocean upper $(0-60 \mathrm{~m})$ layer. The reliability of model forecasts of such situation is largely determined by the development level of the ocean upper layer thermal processes observation system. Remote observation methods (widely used for solving the environmental monitoring problems) require validation on contact measurement data and do not provide the subglacial ocean layer monitoring. For understandable reasons the network of habitable drifting stations of the "North Pole" type can not also be realized with the required spatial-temporal resolution.

Within the framework of the abovementioned UpTempO project, the problem of operational systematic monitoring of thermal processes in the upper subglacial ocean layer is solved by applying BTC60/GPS/ice-type drifters.

Long-term series of data on spatial-temporal variability of such layer structural feature as sub-surface temperature maximum, the formation mechanisms of which remain understudied [13, 14], are among the most interesting results of the Arctic Ocean upper layer temperature profiling. The results of drifter monitoring of vertical temperature distribution in the ocean upper layer near the North Pole according to ID246740 drifter data (drift trajectory is given in Fig. 2, c) are represented in Fig. 7. The explanations in Fig. 7 are taken from [15].

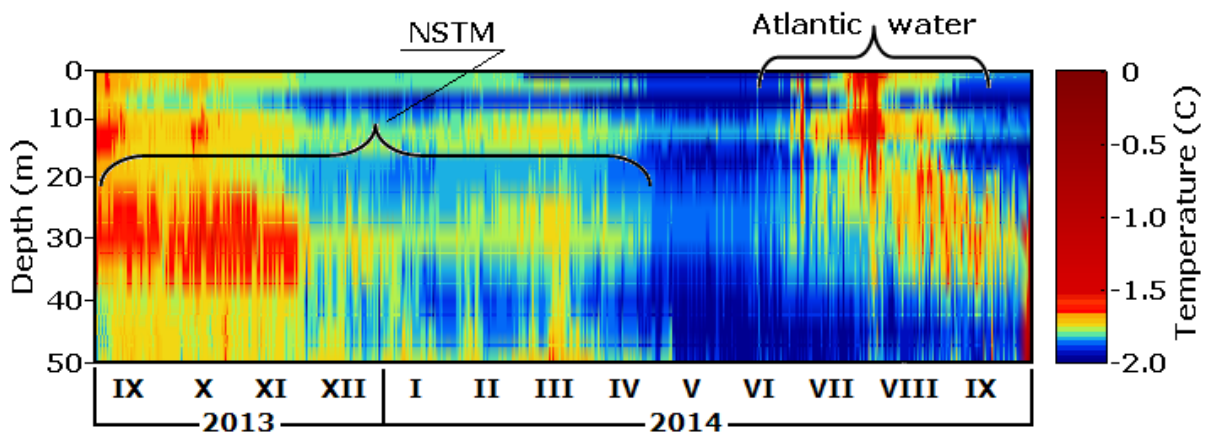

Fig. 7. Subglacial ocean layer thermal structure near the North Pole according to ID246740 drifter data (September 2013 - October 2014) 
Sub-surface temperature maximum was clearly seen in autumn - winter 2013 and in spring 2014. Mean depth of the maximum axis during the observation remained stable and made up $\sim 30 \mathrm{~m}$.

The results obtained during the long-term drifter monitoring in the Arctic allow us to refine modern concepts of the sub-surface temperature maximum genesis and evolution, seasonal changes in the heat content of the surface layer [10].

In a number of cases temperature profiling data provides an opportunity to assess the ice thickness and its spatial-temporal variability. The sections of ID246740 and ID247800 drifter trajectories in the Central Arctic are shown in Fig. 8, $a$. The areas with the temperatures below $-1.8^{\circ} \mathrm{C}$ are clearly seen in the graphs in Fig. $8, b$ which were plotted on the basis of temperature measurement results on the temperature lines upper horizons of the mentioned drifters. According to the thermal variability, ice thickness at the drift sections denoted by markers reached $4-5 \mathrm{~m}$. Dynamic characteristics of the ice formation processes can be obtained using the results of drifter trajectory measurements acquired by the data of built-in GPS receivers.

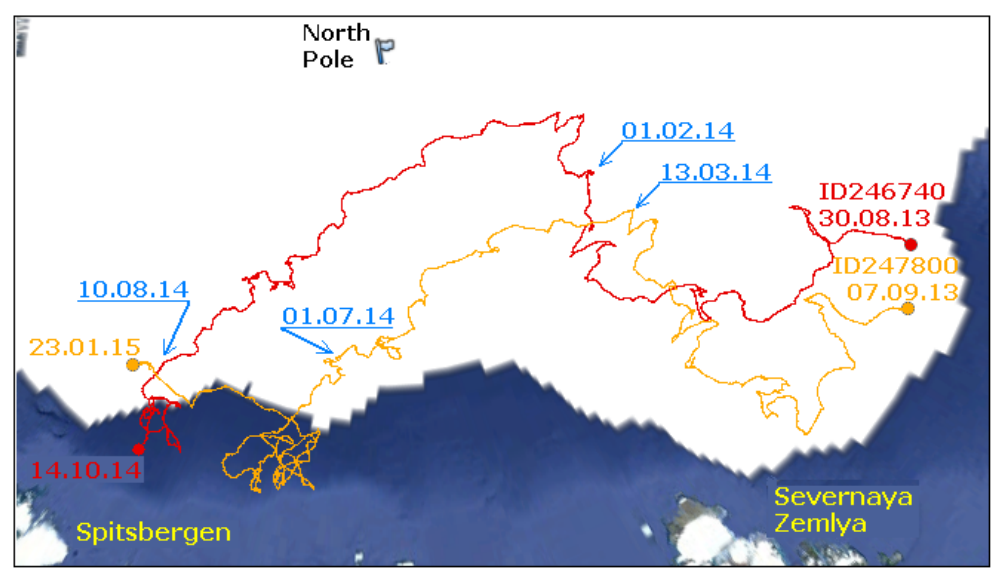

$a$

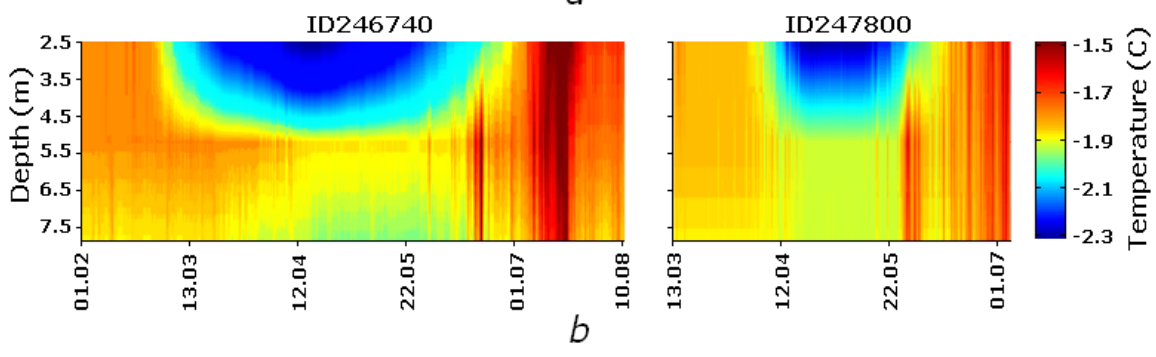

Fig. 8. The results of ice thickness assessment according to temperature measurement data on the upper temperature line horizons of ID246740 and ID247800 drifters: $a$ - the trajectories of drifts; $b-$ time series of temperature profiles. The sections of trajectories corresponding to the temperature profile series by the time are marked by arrows

Conclusions. The results of the present analysis should be considered as preliminary. Nevertheless, they convincingly demonstrate the creation of an effective autonomous tool for long-term operational monitoring of the ice field dynamics, 
thermal processes in the upper ocean layer (including the under-ice one) and the atmospheric pressure fields. Temperature profiling drifters of BTC60/GPS/ice type can be considered as a basic mean of reliable and economical observation system for the ocean polar regions. As a segment of a system for covering the situation in the Arctic, drifter observational network will provide the increase of navigation and oil platforms operation safety on the Arctic shelf, validation of data obtained using the remote methods, the increase of hydrophysical field modeling accuracy. It also will allow reducing the probability of erroneous meteorological forecasts and the ones of ice conditions, refining and even changing the existing concepts of the atmosphere - ice - ocean system interaction character in the Arctic basin.

Acknowledgements. The study is carried out within the framework of the State Order No. 0827-2014-0011 "The research of regularities of marine environment condition changes on the basis of operational observations and the data of marine area condition nowcast, forecast and reanalysis system” (“Operative oceanography" code).

\section{REFERENCES}

1. Pisarev, S.V., 2012. Opyt Primeneniya Avtomaticheskikh Dreyfuyushchikh Ustroystv dlya Issledovaniya Vodnoy Tolshchi i Ledovogo Pokrova Arktiki v Nachale XXI v. [Experience of Using Automatic Drifting Devices to Study the Water Column and Ice Cover in the Arctic at the Beginning of XXI Century]. Arktika: Ekologiya i Ekonomika, [e-journal] (4), pp. 66-75. Available at: http://arctica-ac.ru/docs/4(8)/066-075_ARKTIKA_8_2012.pdf [Accessed 5 November 2016] (in Russian).

2. Polyarnye Stantsii Rossiyskogo Sektora Arktiki [Polar Stations in the Arctic Russian Sector]. [online] Available at: http://geographyofrussia.com/polyarnye-stancii-rossijskogo-sektoraarktiki/ [Accessed 10 October 2016] (in Russian).

3. Sybrandy, A.L., Niiler, P.P., Martin, C., Scuba, W., Charpentier, E. and Meldrum D.T., 2009. Global Drifter Programme - Barometer Drifter Design Reference. DBCP Technical Document No. 4, WOCE Report No. 134/95, SIO Report No. 95/27, 47 p. Available at: http://www.jcommops.org/doc/DBCP/svpb_design_manual.pdf [Accessed 10 October 2016].

4. Tolstosheev, A.P., Lunev, E.G. and Motyzhev, S.V., 2014. Analiz Rezul'tatov Naturnykh Eksperimentov s Termoprofiliruyushchimi Dreyfuyushchimi Buyami v Chernom More i Drugikh Rayonakh Mirovogo Okeana [The Analysis of Field Experiment Results with Temperature-Profiling Drifting Buoys in the Black Sea and in Other Regions of the World Ocean]. Morskoy Gidrofizicheskiy Zhurnal, (5), pp. 9-32 (in Russian).

5. Rakovich, N.N., 2000. Osnovy postroeniya setey MicroLAN [Fundamentals of MicroLAN networks]. Chip News, (6), pp. 14-17. Available at: http://www.chipnews.ru/html.cgi/arhiv/00_06/stat_14.htm [Accessed 1 November 2016] (in Russian).

6. Merkin, D.R., 1980. Vvedenie v Mekhaniku Gibkoy Niti [Introduction to the Flexible Thread Mechanics]. Moscow: Nauka Publ., 240 p. (in Russian).

7. UpTempO. Measuring the Upper Layer Temperature of the Polar Oceans. [on-line] Available at: http://psc.apl.washington.edu/UpTempO/UpTempO [Accessed 10 November 2016].

8. Bayankina, T.M., Litvinenko, S.R., Kryl’, M.V. and Yurkevich N.Yu., 2017. Database of the Operational Drifter Observations in the Arctic Region. Physical Oceanography, [e-journal] (2), pp. 65-74. doi:10.22449/1573-160X-2017-2-65-74

9. Motyzhev, S.V., Lunev, E.G. and Tolstosheev, A.P., 2016. The Experience of Barometric Drifter Application for Investigating the World Ocean Arctic Region. Physical Oceanography, [e-journal] (4), pp. 47-56. doi:10.22449/1573-160X-2016-4-47-56 
10. Steele, M., Ermold, W. and Zhang, J., 2011. Modeling the Formation and Fate of the Nearsurface Temperature Maximum in the Canadian Basin of the Arctic Ocean. J. Geoph. Res., [e-journal] 116(C11), C11015. doi:10.1029/2010JC006803

11. Alekseev, G.V., Pnyushkov, A.V., Ivanov, N.E., Ashik, I.M., Sokolov, V.T., Golovin, P.N. and Bogorodsky, P.V., 2009. Kompleksnaya Otsenka Klimaticheskikh Izmeneniy v Morskoy Arktike s Ispol'zovaniem Dannykh MPG 2007/08 [Assessment of the Climatic Changes in the Marine Arctic with IPY 2007/08 Data]. Problemy Arktiki i Antarktiki, 1(81), pp. 7-14. Available at: http://www.aari.ru/misc/publicat/paa/PAA-81/PAA81-01\%20(7-14).pdf [Accessed 10 November 2016] (in Russian).

12. Steele, M. and Dickinson, S., 2016. The phenology of Arctic Ocean Surface Warming. J. Geoph. Res., [e-journal] 121(9), pp. 6847-6861. doi:10.1002/2016JC012089

13. Jackson, J.M., Carmack, E.C., McLaughlin, F.A., Allen, S.E. and Ingram, R.G., 2010. Identification, Characterization, and Change of the Near-Surface Temperature Maximum in the Canada Basin, 1993-2008. J. Geoph. Res., [e-journal] 115(C5), C05021. doi:10.1029/2009JC005265

14. Iakshina, D.F., Golubeva, E.N., 2016. Issledovanie Mekhanizmov Formirovaniya Podpoverkhnostnogo Maksimuma Temperatury v Kanadskom Basseyne Severnogo Ledovitogo Okeana [The Study of Mechanisms of the Near-Surface Temperature Maximum Formation in the Canada Basin of the Arctic Ocean]. Interekspo Geo-Sibir', [e-journal] 4 (1), Pp. 125-129. Available at: https://elibrary.ru/item.asp?id=26156842 [Accessed 20 November 2016] (In Russian).

15. Arctic Research Center, 2014. Report on the Workshop "Near-slope observations in the Eurasian and Makarov Basins of the Arctic Ocean”. Arlington, USA: University of Alaska Fairbanks, 27 p. Available at: http://research.iarc.uaf.edu/NABOS2/pubs/Arlington_Workshop_April_2014.pdf [Accessed 14 December 2016]. 